\title{
Engaging Aerospace Students Using Interactive Web-Based Techniques
}

\author{
Adeel Khalid \\ Systems and Mechanical Engineering, Kennesaw State University, Marietta, USA \\ Email: akhalid2@kennesaw.edu
}

Received 19 April 2016; accepted 3 June 2016; published 6 June 2016

Copyright (C) 2016 by author and Scientific Research Publishing Inc. This work is licensed under the Creative Commons Attribution International License (CC BY). http://creativecommons.org/licenses/by/4.0/

c) (i) Open Access

\begin{abstract}
Most engineering courses require some level of work to be done by students using internet. A vast majority of material taught in classes is available online. Theoretically, a student could learn almost everything they want from the online resources. In this research, a comparative study is done between students learning and understanding when some basic aerospace concepts are taught in a traditional lecture based classroom versus when students are told to look for the same material on the internet. The results indicate that, although all the material taught in the classroom is available on the internet, students do not perform better when they exclusively use internet for learning. However a traditional lecture based class coupled with internet resources yields the favourable results.
\end{abstract}

\section{Keywords}

Web-Based, Interactive, Aerospace, Student Engagement

\section{Introduction}

The goal of this research is to explore the best classroom learning approach for engineering students. The idea of deductive vs. inductive techniques has been explored extensively in liberal arts. In recent studies, it has been shown that students learn better when they are given the task of student centered active learning in a classroom [1] [2]. The inductive techniques of learning have been successfully implemented. In the traditional deductive methodology, the instructor teaches students a certain concept and then gives a test, whereas; the inductive approach is student centered and interactive. A topic is introduced to the students, they are allowed to do their own search through exploration, and then they present their findings and take a quiz at the end [3]. In the liberal arts disciplines, it is found that through the inductive approach, students learn faster, better and retain longer. Inductive learning is active learning. It keeps all the students involved and interested. The idea of this study is to ex- 
plore and see if similar approach can be applied to the engineering students. The style, in which the engineering curriculum is presented, is significantly different from that of the liberal arts. The liberal arts courses are traditionally knowledge based, whereas engineering courses are knowledge and problem solving based, critical thinking intensive and often numerically challenging. In this study, the investigators will explore whether the inductive techniques successfully implemented in the liberal arts are also applicable in the engineering disciplines [4].

The study is based on the hypothesis that the use of multimedia devices and online learning in classrooms can significantly enhance student learning and retention. An experimental research study is conducted on multidisciplinary engineering students. The control group is taught certain aerospace engineering concepts using traditional lecture based methodologies. The experiment group is taught the same material by letting students learn the material by exploring on their own using the World Wide Web. Bias is removed by using students and instructors, with no prior acquaintances, in each group. Similarly the material introduced to each group, although engineering based, is unique in the sense that the students have not been previously exposed to it. The results of the two groups are compared and the hypothesis is tested. Student performance in each group is also compared based on age, ethnicity, major, year of study in college, and previous job experience.

\section{Hypothesis}

Student learning in an engineering class can be improved through interactive online classroom activities including supervising students to learn the material on their own, by letting them explore through the text book, internet, and use of multi-media devices e.g. cell phone, IPod touch, Ipad, etc.

\section{Teaching Approaches}

To verify the hypothesis, study these approaches, collect data, and compare results, the following different styles of teaching are used in several different engineering classes of similar level.

Case A: Traditional classroom style of teaching using Power Point slides, and white/blackboard is employed. The instructor does most of the talking and students listen passively. At the end of the study, students take a quiz.

Case B: The instructor uses props to describe different concepts. Students listen, are encouraged to ask questions, and see and touch the model (prop) and then take the test at the end of the lecture.

Case C: The instructor introduces the topics of discussion and asks student to explore the subject matter. Students use internet, handheld devices, books, discussion, and other sources to collect information on their own. Instructor is present to answer any questions during the exploratory period. Students are also encouraged to discuss amongst each other. Students take the test at the end of the exploratory period.

All three groups are given equal amount of time e.g. in Case A, if the instructor takes 15 minutes to explain a concept by writing information on the board, or in Case B by using props, the same amount of time is given to students in case $\mathrm{C}$ to explore the subject matter on their own.

\section{Data Collection}

After the lecture in Case A and B, or self-guided study in Case C, students are given a quiz from the material that they are required to learn. At the end of the quiz, there is a small survey. Following data is collected from the students as part of the test at the end of the study.

- Age;

- Major;

- Year of study in college (freshman, sophomore, junior, senior etc.);

- Current job title (if any);

- Previous job title (if any).

This data helps isolate the outliers. It also helps the investigators put results of different groups in different categories and draw inferences.

\section{Test Questions}

Test questions are based on the topics introduced in class, lecture given in Case A, props used in Case B, and the 
instructions given to the students to find the relevant material using the internet. Since the same material is covered in all three cases, identical quizzes are given in all three cases. Screenshots of the quiz given to students are shown in Figures 1(a)-(c).

Students are also introduced the equation of lift. Questions 3, 4, and 5 can be answered when the equation of lift is understood.

$$
L=\frac{1}{2} \rho v^{2} A C_{L}
$$

where

- $L$ is lift force,

- $\rho$ is air density,

- $v$ is true airspeed,

- $A$ is planform area, and

- $C L$ is the lift coefficient at the desired angle of attack, Mach number, and Reynolds number [5].

In Case C, students are given the resources that they can explore on the internet to understand the equation of lift. The same quiz is given to all groups. Questions 3, 4, and 5 help determine whether students can understand mathematical equations and engineering formulas on their own in Case C. The relationships between lift produced by the wings of an aircraft and aircraft velocity, air density, and angle of attack can only be completely

Sample Quiz

Name: $\underline{\text { Anonymous }}$

\section{Engineering Study Quiz}

Time Allowed: $15 \mathrm{~min}$

Total Points: 15

\section{Question\#1}

Fill in the blocks by writing the names of parts of the airplane.

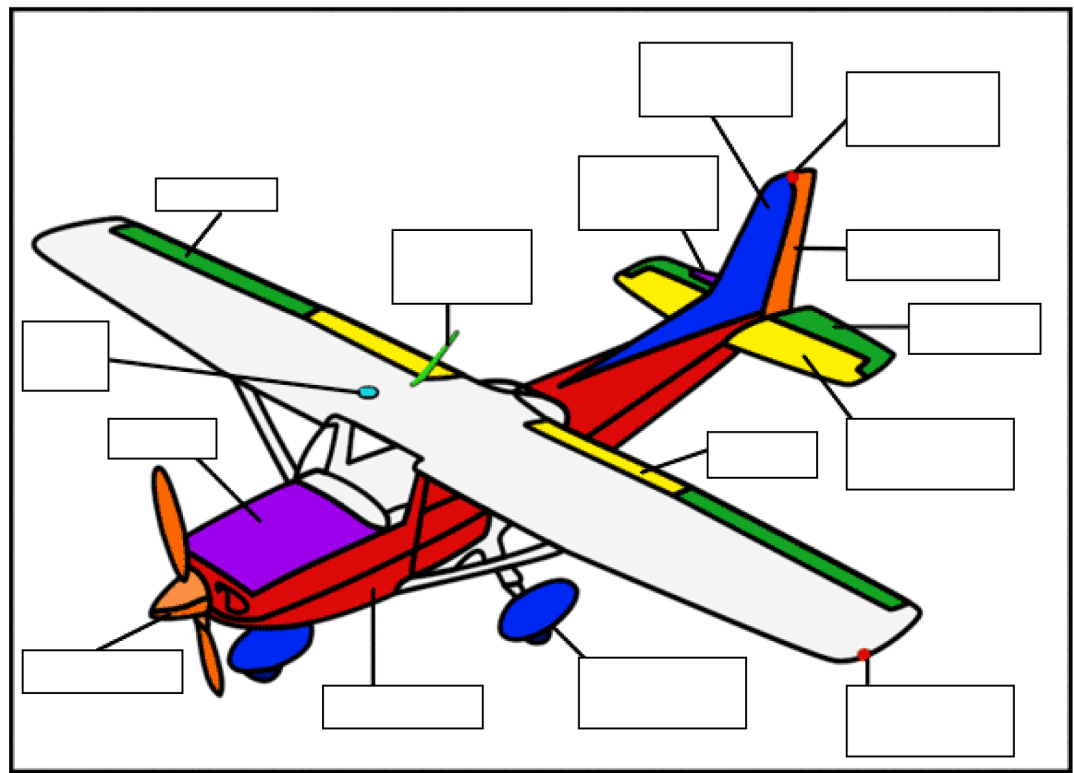

(a) 
Sample Quiz

\section{Question\#2}

Fill in the following blocks by writing the motions of the airplane.

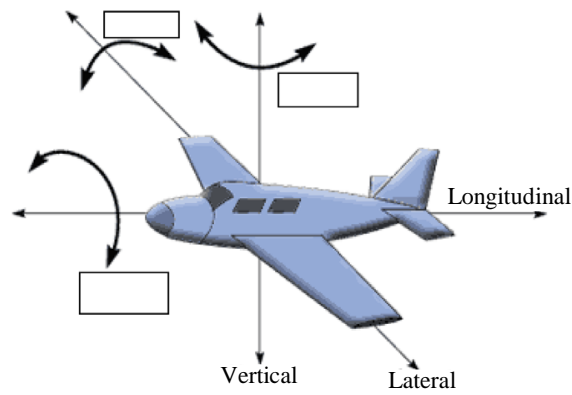

\section{Question\#3}

How does the lift produced by the wings change with the increasing velocity (circle one).
a) Does not change with velocity
b) Decreases linearly with velocity
c) Decreases as squared of velocity
d) Increases linearly with velocity
e) Increases as squared of velocity
f) Increases as cube of velocity

\section{Question\#4}

How does the lift produced by the wings change with the increasing air density (circle one).
a) Does not change with air density
b) Decreases linearly with air density
c) Decreases as square of air density
d) Increases linearly with air density
e) Increases as square of air density
f) Increases as cube of air density

Sample Quiz

\section{Question\#5}

How does the lift produced by the wings change with increasing angle of attack (circle one).
a) Does not change with angle of attack
b) Decreases linearly with angle of attack
c) Decreases as square of angle of attack
d) Increases linearly with angle of attack
e) Increases as square of angle of attack
f) Increases as cube of angle of attack

The following information is optional but will help us better analyze our results.
Age
Race/Ethnicity
Major
Year of study is college
Current or previous job title
Would you prefer to use internet to learn material in all your classes, Why?

Figure 1. (a) Screenshot of the quiz questions; (b) Screenshot of the quiz questions (Continued); (c) Screenshot of the quiz questions (Continued). 
understood if the student learns and understand the equation of lift. The comparison of student performance in questions 1 , and 2, which are knowledge based, with questions 3, 4, and 5, which are analytical, help determine whether students learn different types of knowledge using the same method of teaching. Evaluation of performance of students in questions 3, 4, and 5 help determine whether there is a difference in student learning when taught by the instructor (Case A and B) and when students learn formulas and engineering equations on their own (Case C).

The last question in the survey, which asks about student's perception of internet usage to learn class material, will help determine whether they actually learn material better or whether they perceive it that way and vice versa.

\section{Qualitative Results}

The results obtained from the above survey are compared both qualitatively and quantitatively for each case. Some of the qualitative student responses received for Case A are listed in Table 1.

Case A indicates that students who do not to use the internet and are taught using the traditional lecture based technique, generally like the idea of being able to use the computer, hand-held devices etc. to access to internet to learn the material. The qualitative results obtained for Case B are shown in Table 2.

\section{Table 1. Qualitative responses for Case A.}

\begin{tabular}{ll}
\hline Like & Like the option of different ideas \\
& $\bullet$ The information is always available \\
& $\bullet$ Liked it-all very interesting \\
& $\bullet$ Good Graphics \\
\hline Dis-Like & \\
\hline & - Dislike: Ambiguity in learning goals
\end{tabular}

Table 2. Qualitative responses for Case B.

\begin{tabular}{|c|c|}
\hline \multicolumn{2}{|l|}{ Like } \\
\hline & $\begin{array}{l}\text { - It was fine-I wish you pointed more to the diagram } \\
\text { - It provided a good visual aid } \\
\text { - Liked the props } \\
\text { - Love it! Its there-lets use it } \\
\text { - Quick/Easy access to information } \\
\text { - The diagram was helpful } \\
\text { - I am sorry I was not paying attention, I was reading something else-You teach in a really good way. This } \\
\text { - } \text { university needs more professors like you. } \\
\text { - Students can focus on what they need to } \\
\text { - Helped but not needed } \\
\text { - it was fast and promoted multimedia use } \\
\text { - I actually liked it better than a bunch of words on the white board } \\
\text { - It helped with graphical representation } \\
\text { - } \quad \text { Positive: Fast detailed information, }\end{array}$ \\
\hline \multicolumn{2}{|l|}{ Dislike } \\
\hline & $\begin{array}{l}\text { - Hard to see } \\
\text { - Bad: It is difficult to take notes and absorb all material because power point and graphics allow for quick } \\
\text { and in depth presentation but there is often too much, too fast to absorb it all } \\
\text { - Negative: sometimes information is not accurate }\end{array}$ \\
\hline
\end{tabular}


In Case B, students are taught using the traditional lecture; and additionally relevant props are used. In this study, a model aircraft is used. The instructor points to different parts of the aircraft on the model while explaining their functions. The maneuvers of the aircraft are also discussed using the model aircraft. Case B indicates that students who do not use the internet and are taught using the traditional lecture based technique and the use of props, generally like the idea of being able to use the computer, hand-held devices etc. to learn the material. The qualitative results obtained for Case $\mathrm{C}$ are shown in Table 3.

In Case C, students are not taught using the traditional lecture, but are instead given the flexibility to search for material online. The class is held in a computer lab where all students have access to computers. Students are directed to go to pre-selected websites to look for information. Students are also informed about the possible questions on the test. The instructor is available to help them search for material, direct them to the correct sources for information and answer any questions. The instructor also interjects several times to ensure that all the students are looking for the material that they are required to find.

As seen in Table 1 and Table 2, students perceive that if they are allowed to use the internet to search for material, they will learn better. However, when they are given the option of using the internet in Case C, a number of students realize that it is not the best way for them to learn. Some students indicate that they get information overload, some claim of dis-organization, and yet others state that the instructor is not actively involved in teaching. The qualitative data indicates that there are mixed feelings amongst students about the use of internet to learn material. Until they are exposed to the method, they are either un-sure about how it would work or think that it would facilitate learning. On the other hand, when self-guided learning is encouraged and they are given the freedom to look for material on their own, with the instructor's moderation, about 50\% of the students claim that the use of internet does not help them in learning. This qualitative data is subjective-it is the individual's interpretation of the event but is useful to understand the contextual details. It is rich, but less able to be generalized. Data between Cases A, B, and C are also compared quantitatively.

\section{Quantitative Results}

To be able to test the hypothesis, it is important to analyze the quantitative data. The total number of students surveyed in all cases combined is 150 . The overall scores in all cases for each question are shown in Figure 2. It is observed that students generally perform better in questions 2, 3, and 4 compared to question 1 . Question 1 has several parts - the idea is to memorize the names of parts of the aircraft. Students tend to understand the equation of lift better and answer questions based on that, than memorizing the names of the parts of the aircraft.

As shown in Figure 3, most of the participants are in the 20 - 23 year old age group. The common denominator amongst all these age groups is that they are all undergraduate students and have not taken any Aerospace related classes in the past.

Figure 4 shows the number of student participants in different majors. The Civil and Mechatronics engineering majors at Southern Polytechnic State University are the largest programs in the Division of Engineering. The typical core classes in these disciplines have more students than the other majors. There is a large number of Mechanical Engineering Technology students on campus. But the survey is not taken in any of the MET core classes. The presence of MET students in participants reflects those students taking classes outside their major.

The first set of results is shown in Figure 5 and Figure 6. It is important to observe that generally younger students perform better than older students in all categories. This trend can specially be seen in Case A where the traditional classroom method of instruction is used. It can also be observed that students in early 20s performed better in Case B. At this age, they have most likely taken their first year of college courses and are used to the college environment. When a lecture is given, and props are used, this age group tend to learn the most. The overall scores by age group in all three cases are shown in Figure 6. It can be seen that the general trend is a decrease in performance with age.

Although the concepts introduced in this study are generic, it appears that students in certain majors tend to perform than other majors. For example, as shown in Figure 7, Mechatronics and Electrical Engineering majors tend to perform better than Civil, Construction, and Civil Engineering Technology major students. This may be due to their interest in the field-which indirectly dictates their motivation to participate in the study and learn the material.

The average scores on the basis of cases for students in different years in college are shown in Figure 8 and Figure 9. The trend is similar to the trend seen in Figure 6. Students in their early years of college tend to perform better in all categories and all cases. The author has observed this trend in other classes, camps and work 
Table 3. Qualitative responses for Case C.

Like

- Easily Accessible information

- Good-Not bad

- Very Helpful

- Helps being able to search yourself

- I liked the variety

- More Interesting

- Liked but not enough time, Good material

- Fun

- Very Helpful

- Interactive

- I am a visual learner, so images are helpful. Also the fact that info on the internet is virtually endless, means that I can find what I want, as long as I know what I am looking for.

- Informative for 15 minutes

- Like: Internet is fine for learning,

- I was able to adapt my learning to a style that works for me rather than how the instructor chooses to teach

- Freedom

- Interesting approach-need more research time though

- I thought it was helpful

- Greater variety of sources

- Eye problem, but increases learning

- Liked the ability to access more information, but had too many ways to get distracted from the goal

- New

- Freedom to concentrate on what you found interesting was good-I did'nt know what I was expected to learn except in a broad sense

- Like, I can learn on my own pace, and view what I want

- I prefer this method

- Liked learning about aircraft

- I liked it!

- Variety of sources

Dislike

- Searching would have been too vague if I had not already known exactly what would be on the quiz

- Nothing-All information was given easily. Lack of time for memorization

- Too much information at one time

- Dislike (4 responses)

- Non-Credible sources

- Knowledge needed is misguiding

- Not enough time to learn 


\section{Continued}

- Works well with short term memory but makes students much less apt to truly understand the material

- Dislike: lack of professor's involvement in student's learning

- It can be misleading, as some sites have different information than what you want the student to learn

- Dislike-motivation to sit still

- Use of internet allows for many different websites which could lead to a lack of information depending on the website

- It was different-student is not guaranteed to get the correct information

- Internet searches do not always produce desired results

- Not targeted enough. Too easy to find false, irrelevant, or even too detailed (or under-detailed) information

- I did not have a computer-If I wanted to learn from the internet, I would have stayed at home. This is the biggest copout on Education Ever!

- Very Busy

- So many places to look, unsure where most of the questions for quiz would come from

- Unsure of information credibility

- Was not clear about assignment

- Lack of a computer to use

- Search overload

- Did not really know specifically what to search for. Too broad of an information source

- More interactive but not as organized

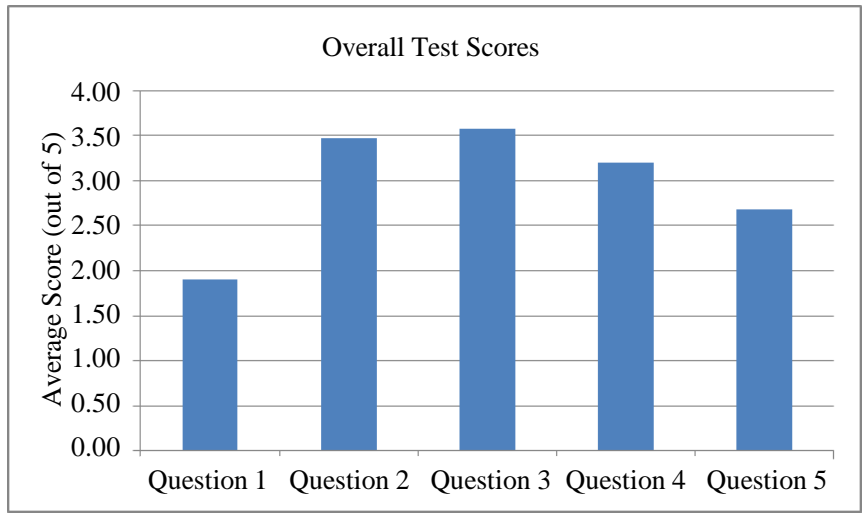

Figure 2. Overall averages per question-all cases combined.

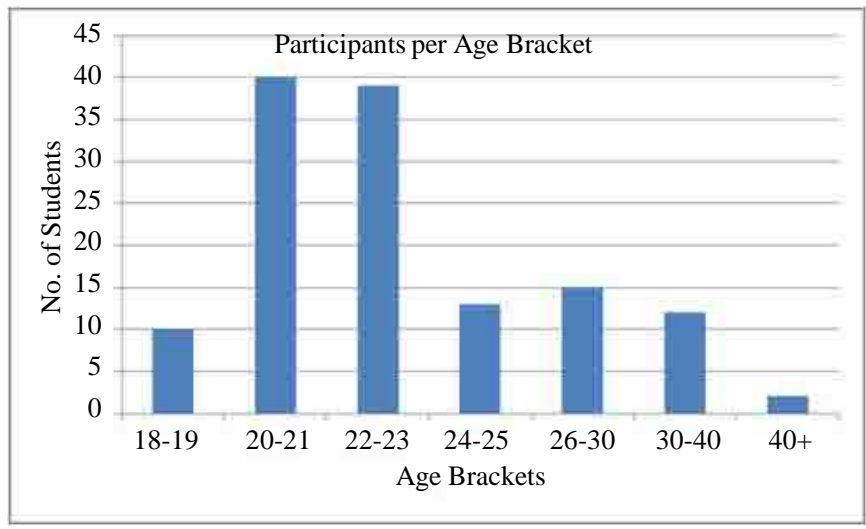

Figure 3. Participant age groups. 


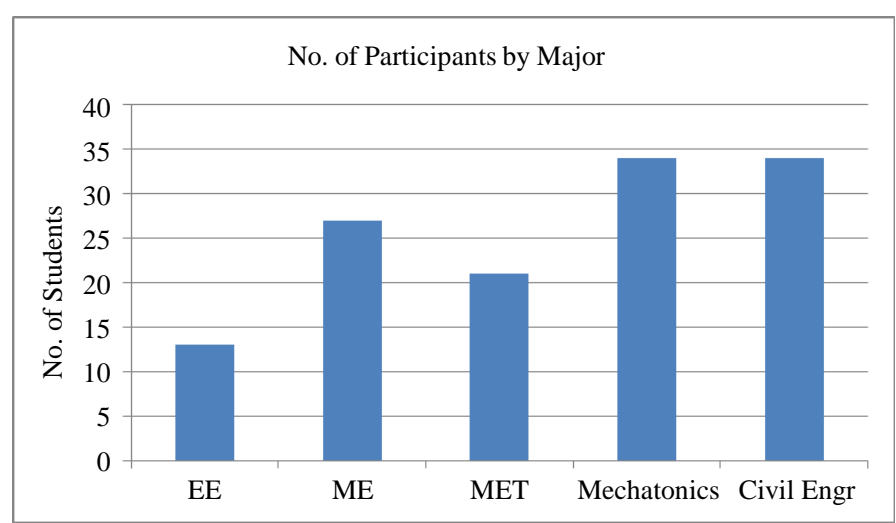

Figure 4. Number of participants by Major.

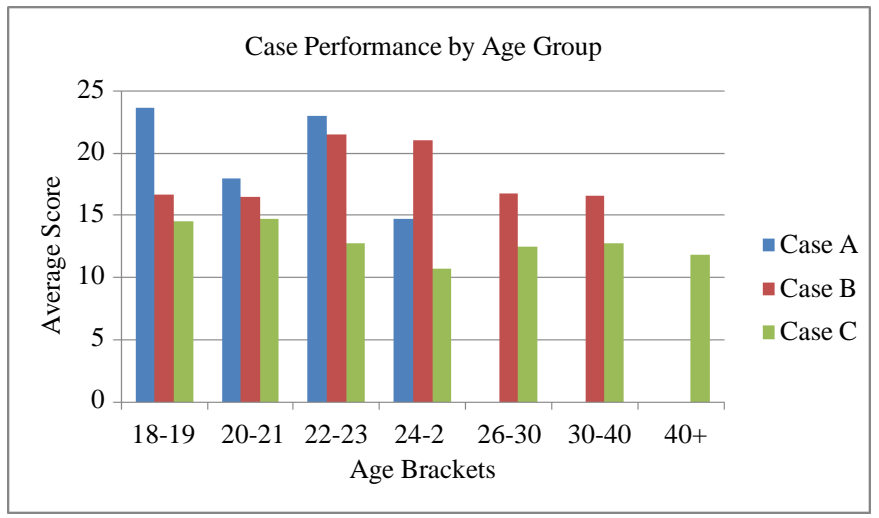

Figure 5. Case performance by Age Group.

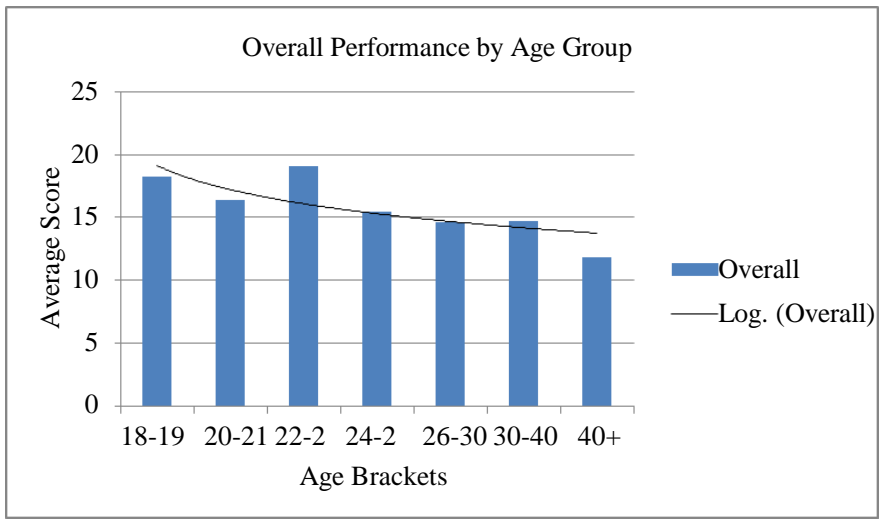

Figure 6. Overall performance by Age Group.

shops as well. The author conducts Aerospace Engineering summer camps for middle and high school students, 12 - 18 year olds, every year on the campus of Southern Polytechnic State University. In the author's experience, the best performers are usually the youngest, typically 12 year olds in the camp. The high level of performance seen in younger groups in this study can also be attributed to the fact that the university is starting a new Aerospace Engineering (AE) program. The freshmen and sophomore students have interest in this field because they understand that they can earn a minor in AE. This motivation does not exist in the senior level students who are typically close to graduation and are not interested in taking any more college courses. They are usually looking to get out of college and get a job. Part of it may also have to do with intrinsic motivation and its variation with age. Some researchers believe that there is only a single kind of intrinsic motivation, which can be described as a 


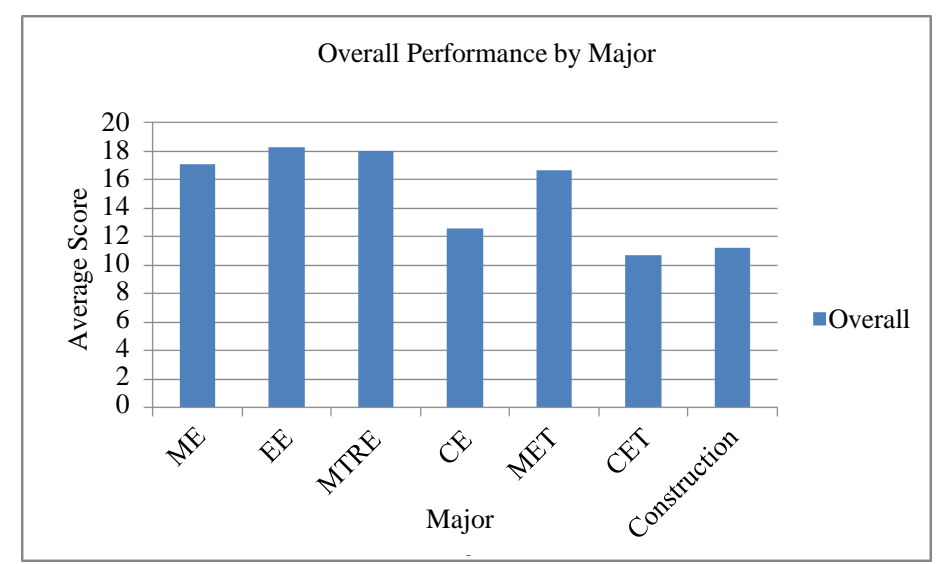

Figure 7. Overall performance by Major.

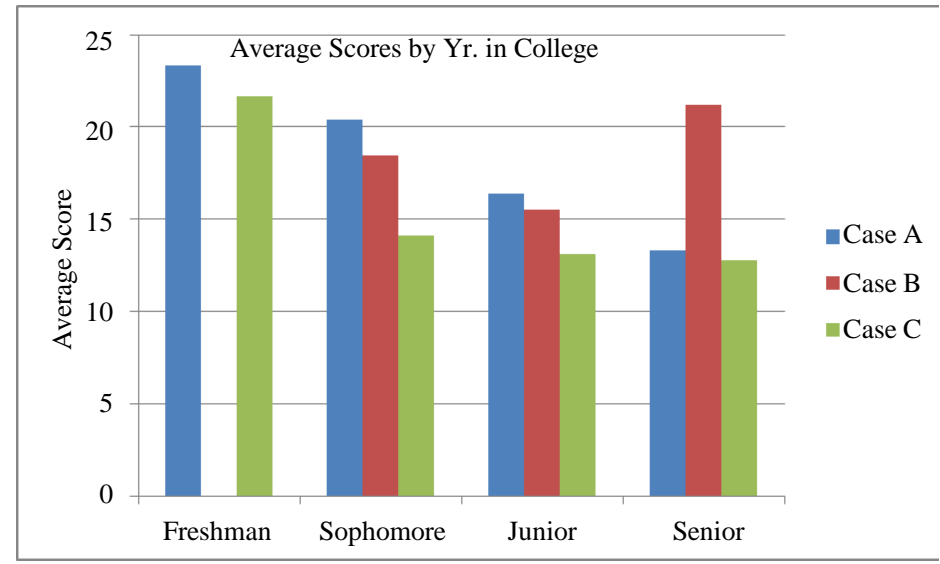

Figure 8. Case performance by year in college.

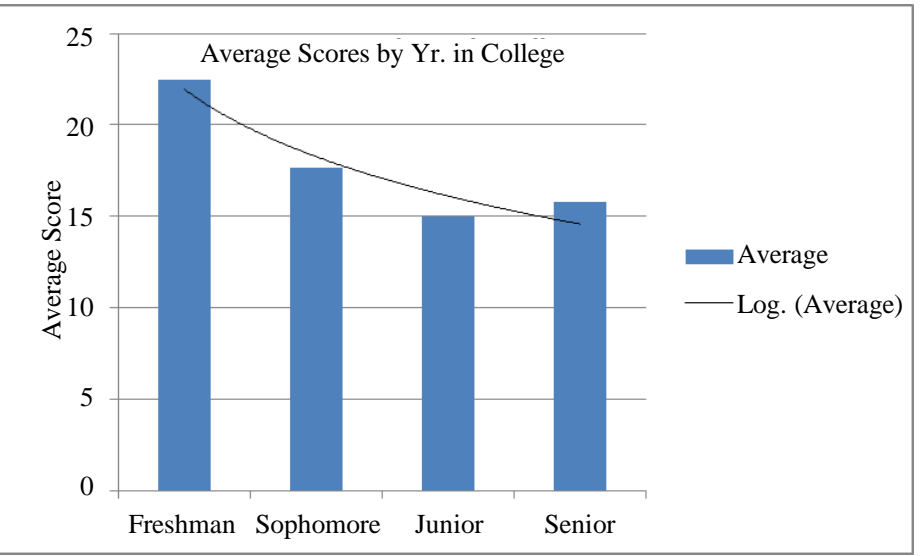

Figure 9. Overall performance by year in college.

motivation to engage in activities that enhance or maintain a person's self-concept [6]. Malone and Lepper [7] have defined intrinsic motivation more simply in terms of what people will do without external inducement. Intrinsically motivating activities are those in which people will engage for no reward other than the interest and enjoyment that accompanies them. Malone and Lepper have integrated a large amount of research on motivational theory into a synthesis of ways to design environments that are intrinsically motivating. In this research, Case $\mathrm{C}$ is designed to motivate students to learn on their own. 
The overall performance of students in the three cases is shown in Figure 10. The total possible score is 25. Contrary to the expected result, students do not perform as well in Case C, as they do in Cases A and B. The average score in Case C, is significantly lower than those in Cases B and C. This result does not support the hypothesis. Students are expected to learn better when they are given the opportunity to explore on their own. The instructor is present at all times to guide them and answer any questions. The best results are seen in case B, where students learn not only by listening to the lecture, but also by seeing the model aircraft. They relate and remember better when a real life example is presented. The author believes that students do not perform well in Case $\mathrm{C}$ because they have not been exposed to this idea of self-guided learning in the past. In all their years of education, they have mostly been passive learners. Due to the current education system, in every class they have taken since the kindergarten, the instructor is the source of all knowledge and students are expected to learn directly from them. In this exercise, they are expected to learn from a different source. So the role of the instructor changes from being the feeder of knowledge to a facilitator. A number of students are either not familiar or not comfortable with this new approach. The author believes that student-centered, inductive, active learning techniques are the best method to engage engineering students and can help them learn and retain the material. Students need to be trained for this new method of learning. If they are exposed to this method for a significant period of time, their performance will increase. It is reasonable to expect that students will perform better in the long run if they are subjected to the inductive style of teaching.

\section{Quantitative Results}

Cases A and B are compared using t-test with a 95\% confidence interval. The first 19 observations are used for Case B. The results indicate that the two means are not statistically different. Similar results are obtained when Case A is compared with the last 19 observations for Case B. Results are listed in Table 4.

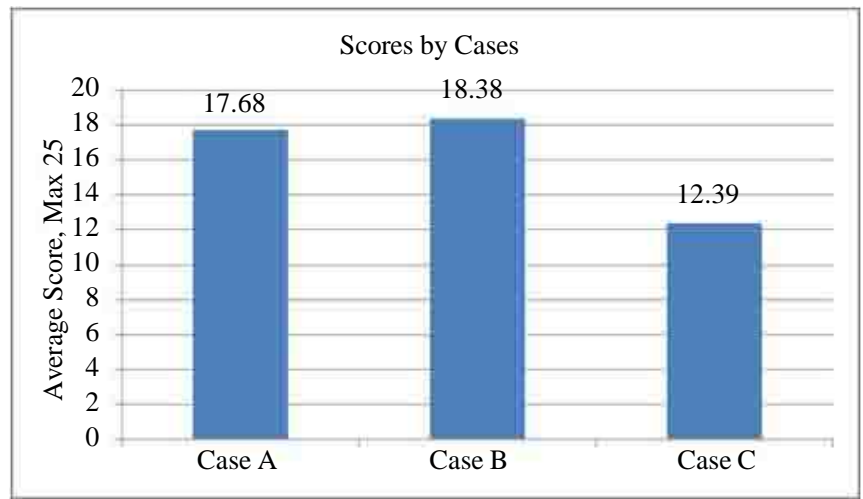

Figure 10. Scores by Cases.

Table 4. T-Test between Cases A and B.

\begin{tabular}{ccc}
\hline t-Test: Paired Two Sample for Means & & Case A $B$ \\
\hline Mean & 17.68421 & 17.17544 \\
Variance & 39.01819 & 41.75763 \\
Observations & 19 & 19 \\
Pearson Correlation & 0.103757 & 0 \\
Hypothesized Mean Difference & 18 \\
$\mathrm{df}$ & 0.260634 \\
$\mathrm{t}$ Stat & 0.398666 \\
$\mathrm{P}(\mathrm{T} \leq \mathrm{t})$ one-tail & 1.734064 \\
$\mathrm{P}(\mathrm{T} \leq \mathrm{t})$ two-tail & 0.797333 \\
$\mathrm{t}$ Critical two-tail & 2.100922 \\
\hline
\end{tabular}


Table 5. Single factor ANOVA analysis.

\begin{tabular}{|c|c|c|c|c|c|c|}
\hline Anova: Single Factor & & & & & & \\
\hline \multicolumn{7}{|l|}{ SUMMARY } \\
\hline Groups & Count & Sum & Average & Variance & & \\
\hline Case A & 19 & 336 & 17.68421 & 39.01819 & & \\
\hline Case B & 34 & 625 & 18.38235 & 35.05813 & & \\
\hline Case C & 96 & 1189.6 & 12.39167 & 43.73158 & & \\
\hline \multicolumn{7}{|l|}{ ANOVA } \\
\hline Source of Variation & SS & $d f$ & MS & $F$ & P-value & F crit \\
\hline Between Groups & 1131.184 & 2 & 565.5921 & 13.73128 & 3.43E-06 & 3.05805 \\
\hline Within Groups & 6013.746 & 146 & 41.19004 & & & \\
\hline Total & 7144.93 & 148 & & & & \\
\hline
\end{tabular}

Analysis of Variance (ANOVA) is conducted to determine whether there is a statistical difference between the mean scores for cases A, B, and C. A 95\% confidence interval is used. The null hypothesis is that the means of all the cases are statistically similar and the alternative hypothesis is that they are significantly different. The results of the ANVOA test are shown in Table 5.

The null hypothesis is rejected because $\mathrm{p}<0.01$. In other words, the means are different. A paired t-Test between the averages of Case A and Case B indicates that they are statistically not significant. This demonstrates that the statistical difference exists between Case C and Cases A and B. In other words, students performed worse statistically when they were allowed to use computers to search for material to be taught in the class.

\section{Conclusion}

In this study, the goal is to discover whether engineering students can learn and retain the material, if studentcentered, inductive style of teaching is used. Three different styles of teachings are compared. These are A: traditional lecture style, B: lecture combined with the use of props and C: students use internet to learn the material in class, and the instructor moderates the learning process. Data are collected for the three groups. The expectation is that the use of internet will facilitate better learning. It will engage students, and motivate them to learn the material on their own. Data is compared qualitatively and quantitatively. Students often think that they will learn better if internet is available to them. On the contrary, students perform worse when only the internet is used as the source of learning. It is observed that students learn the material the best in Case B, where props and visual aids are used to facilitate learning. Student performance in Case $C$ is significantly inferior to Cases $A$ and B. The author believes that this is due to the fact that engineering students have most likely never been exposed to the inductive style of teaching. If students are familiar with this method of teaching and learning, and this method is used for a significantly long period of time, it can be expected that students will learn and retain the material better and their performance will improve over the other styles of instruction. The use of internet in conjunction with the traditional lecture based teaching and the use of props is also expected to produce favorable results.

\section{References}

[1] Prince, J.M. and Felder, M.R. (2006) Inductive Teaching and Learning Methods: Definitions, Comparisons, and Research Bases. Journal of Engineering Education, 95, 123-138. http://dx.doi.org/10.1002/j.2168-9830.2006.tb00884.x

[2] Brigham, F. and Matins, J.J. (1999) A Synthesis of Empirically Supported Best Practices for Science Students with Learning Disabilities. Annual International Conference on the Association for the Education of Teachers in Science, Austin.

[3] Inductive and Deductive Methods of Teaching. http://www.articlesbase.com/writing-articles/inductive-and-deductive-methods-of-teaching-1059831.html

[4] Paradowski, M.B. (2009) Deductive vs. Inductive Teaching. Version 3. http://knol.google.com/k/michał-b-paradowski/deductive-vs-inductive-teaching/2qpvzotrrhys1/23

[5] Yoon, J. (2009) Mach Number \& Similarity Parameters. http://www.aerospaceweb.org/ 
[6] Pintrich, P.R. (2003) A Motivational Science Perspective on the Role of Student Motivation in Learning and Teaching Contexts. Journal of Educational Psychology, 95, 667-686. http://dx.doi.org/10.1037/0022-0663.95.4.667

[7] Malone, T.W. and Lepper, M.R. (1987) Making Learning Fun: A Taxonomy of Intrinsic Motivations for Learning. In: Snow, R.E. and Farr, M.J., Eds., Aptitude, Learning and Instruction III: Conative and Affective Process Analyses, Erlbaum, Ê Hillsdale. 